Original Research Paper

\title{
The Use of $\alpha$-MF Signal Peptide Without Spacer for Producing Insulin Aspart Precursor in Pichia pastoris KM71
}

\author{
${ }^{1}$ Popi Asri Kurniatin, ${ }^{1}$ Fifi Fitriyah Masduki, ${ }^{2}$ Neni Nurainy, ${ }^{1}$ Ihsanawati and ${ }^{1}$ Dessy Natalia \\ ${ }^{1}$ Biochemistry Division, Faculty of Mathematics and Natural Sciences, Institut Teknologi Bandung, Indonesia \\ ${ }^{2}$ PT. Bio Farma, Bandung, Indonesia
}

\author{
Article history \\ Received: 24-04-2019 \\ Revised: 11-09-2019 \\ Accepted: 23-10-2019 \\ Corresponding Author: \\ Dessy Natalia \\ Biochemistry Division, Faculty \\ of Mathematics and Natural \\ Sciences, Institut Teknologi \\ Bandung, Indonesia \\ Email: dessy@chem.itb.ac.id
}

\begin{abstract}
A spacer peptide (Glu-Ala repeats) connects N-terminal of a polypeptide precursor to the signal peptide of $\alpha$-mating factor $(\alpha-\mathrm{MF})$ from Saccharomyces cerevisiae. During the polypeptide precursor secretion, the signal peptide will be first cleaved by signal peptidase in the endoplasmic reticulum, followed by $\operatorname{Kex} 2$ endopeptidase and finally the spacer peptide is removed by dipeptidyl aminopeptidase in the Golgi apparatus. In the case of insulin precursor, unfortunately, mixture forms of the insulin precursor containing a spacer peptide and the correct insulin precursor is observed in Pichia pastoris. To overcome this problem, a gene encoding insulin Aspart precursor without the spacer peptide has been constructed and its expression has been investigated in this study. The gene of insulin Aspart precursor has been successfully expressed extracellularly in P. pastoris KM71 with molecular mass of 6306.8 Da as determined by LC-ESI-MS. The expression level of insulin Aspart precursor is affected by aeration, cell density and methanol as an inducer. In shake flask production, the insulin Aspart precursor was optimally produced by $3 \%$ methanol induction every $24 \mathrm{~h}$ for two days, at initial cell density $\left(\mathrm{OD}_{600}\right)$ of 60 and aeration (ratio of culture volume to flask volume) of 1:25. Based on Western blot analysis, there is no intracellular insulin Aspart precursor detected. Therefore, the spacer peptide is not essential for insulin Aspart precursor secretion in P. pastoris and removal of spacer resulted in insulin Aspart precursor homogeneity.
\end{abstract}

Keywords: Spacer Peptide, Insulin Aspart Precursor, Pichia pastoris, Protein Secretion

\section{Introduction}

Insulin is the first approved recombinant protein for therapeutic practice by the United State Food and Drug Administration (USFDA) in 1982 (Leader et al., 2008). Further developments of insulin are the introduction of rapid-acting insulin analogue in 1990 and long-acting basal analogue in early 2000 (Tibaldi, 2014). Insulin Aspart is one of the rapid-acting insulin analogues in which proline (A28) is substituted to aspartatic acid. This amino acid substitution increases the repulsive force between chains and inhibits dimerization of insulin, resulting in a more rapid absorption to circulation after subcutaneous injection (Baeshen et al., 2014; Tibaldi, 2014).

Commercial recombinant insulin is mainly produced in Escherichia coli and Saccharomyces cerevisiae
(Baeshen et al., 2014). Among other alternative yeast expression systems, a methylotrophic yeast Pichia pastoris has become a preferable host because of its excellent features (Baeshen et al., 2014). P. pastoris has been reported to have an equal capacity for expressing and secreting human insulin precursor compared to S. cerevisiae (Kjeldsen et al., 1999). Furthermore, large scale human insulin production in $P$. pastoris has been studied. Human insulin precursor is successfully produced using fed-batch fermentation with protein yield to be 2.26-3.8 g/L (Gurramkonda et al., 2010; Polez et al., 2016; Xie et al., 2008).

The signal peptide of the $\alpha$-mating factor $(\alpha-M F)$ is mostly used for insulin precursor in $P$. pastoris (Daly and Hearn, 2005; Wang et al., 2001). The $\alpha-\mathrm{MF}$ signal peptide is composed of pre-pro-peptide followed by dibasic Kex 2 cleavage site (-KR) and a spacer peptide 
consisting of two or three dipeptides of Glu-Ala (Kurjan and Herskowitz, 1982). The cleavage of signal peptide occurs in the three consecutive steps, namely the pre-peptide is cleaved by signal peptidase in the endoplasmic reticulum; the pro-peptide is then cut by Kex2 endopeptidase; and the Glu-Ala repeats is finally removed by dipeptidyl aminopeptidase A in the Golgi apparatus (Lin-Cereghino et al., 2013). However, a partial cleavage of Glu-Ala spacer from $\mathrm{N}$-terminal of the insulin precursor could occur in S. cerevisiae since a low activity of dipeptidyl aminopeptidase. It is reported that $89 \%$ of the secreted insulin precursor is in the form of Glu-Ala-Glu-Ala-insulin precursor, $2 \%$ of Glu-Ala-insulin precursor, while only $9 \%$ is in the correct form (Thim et al., 1986). The role of a spacer in secretion of insulin precursor is still unclear, whether it helps the Kex2 endoprotease cleavage or secretion directly in $P$. pastoris (Kjeldsen et al., 1999). It is predicted that the Kex2 cleavage is influenced by the amino acids following the $-\mathrm{LEKR}-$, sequence in which a study of the purified Kex2 endoprotease shows a significantly increase activity in the presence of $\mathrm{Arg}$ residue preceding the cleavage site (Brenner and Fuller, 1992).

This paper describes the use of $\alpha-\mathrm{MF}$ signal peptide without a spacer for producing insulin Aspart precursor in $P$. pastoris KM71. A linker - RWR- is introduced to connect the A and B chain of insulin Aspart precursor. The gene encoding insulin Aspart precursor is codon optimized for $P$. pastoris and expressed under a strong and highly regulated $A O X 1$ promoter. Our findings indicate that insulin Aspart precursor is successfully expressed extracellularly despite no spacer peptide addition in the $\alpha-\mathrm{MF}$ signal peptide.

\section{Materials and Methods}

\section{Strain and Materials}

Escherichia coli TOP10 F' as the general cloning host and $P$. pastoris KM71 as the expression host were obtained from Thermo Fisher Scientific, USA. A gene encoding insulin Aspart Precursor (ASP) was chemically synthesized and inserted to pPICZ $\alpha$ A by GenScript, USA. Forward primer AOX1 (5'-GACTGGTTCCAATTGACAAGC-3') and reverse primer AOX1 (5'GCAAATGGCATTCTGACATCC-3') were purchased from Invitrogen (USA).

Restriction enzymes, Spectra LR Protein Marker and Gene Ruler $1 \mathrm{~Kb}$ DNA Ladder were purchased from Thermo Fischer Scientific, USA. Pfu DNA polymerase was obtained from Agilent, USA. Taq DNA polymerase, dNTPs and $\mathrm{MgCl}_{2}$ were purchased from KAPA, USA. ATP Plasmid DNA Mini Kit (ATPBiotech Inc., Taiwan) was employed for plasmid isolation. GenJET Gel
Extraction Kit (Fermentas Life Sciences, AS) was used for DNA purification from gel agarose. Mouse insulin antibody $\mathrm{mAb}$ and Goat anti-mouse IgG antibody (H\&L) [HRP] were supplied by GenScript, USA. The other chemicals for culture mediums, reagents and buffers were purchased from Merck (USA), Bio Basics (Canada) and Sigma-Aldrich (USA).

\section{Transformation of $P$. pastoris KM71}

$P$. pastoris KM71 was used to express the synthetic ASP gene encoding insulin Aspart precursor. The recombinant plasmid pPICZ $\alpha$ A-ASP (Fig. 1) was linearized by restriction enzyme $\mathrm{SacI}$ at $37^{\circ} \mathrm{C}$ for $4-6 \mathrm{~h}$, then analysed by agarose electrophoresis. The linearized plasmid was then purified from the agarose gel. A volume of $5 \mu \mathrm{L}$ containing $400 \mathrm{ng}$ of purified plasmid was used to transform $80 \mu \mathrm{L}$ of $P$. pastoris KM71 competent cells. The competent cells were prepared according to Cregg and Russell (1998). The transformation of $P$. pastoris competent cells were carried out by electroporation on condition $1.5 \mathrm{kV}, 25 \mu \mathrm{F}$ and 200 $\Omega$. A volume of $1 \mathrm{~mL}$ YPD ( $1 \%$ yeast extract, $2 \%$ peptone and $2 \%$ dextrose) was immediately added, and the mixture was then transferred to a sterile microtube and incubated at $30^{\circ} \mathrm{C}$ for $2-4 \mathrm{~h}$ without shaking. An aliquot of $25-100 \mu \mathrm{L}$ cells was grown on YPD plates containing $100 \mu \mathrm{g} / \mathrm{mL}$ zeocin and incubated at $30^{\circ} \mathrm{C}$ for 2-3 days.

\section{Screening of Transformants}

To screen the $P$. pastoris transformants, colonies were grown on YPD plates containing zeocin with a higher concentration $(500-2000 \mu \mathrm{g} / \mathrm{mL})$. Survived colonies on the highest zeocin concentration were selected and screened for Mut $^{\mathrm{s}}$ or $\mathrm{Mut}^{+}$phenotypes by direct PCR using the AOX1 primers. To select and confirm the ability of $P$. pastoris transformant to express insulin Aspart precursor, colony blot was performed (Annibali et al., 2014). Colonies, grown on YPD plate containing $100 \mu \mathrm{g} / \mathrm{mL}$ zeocin, were transferred to a nitrocellulose membrane. The membrane with attached colonies was transferred to $\mathrm{MMH}$ plate (1.34\% yeast nitrogen base, $4 \times 10^{-5} \%$ biotin, $2 \%$ methanol, $2 \%$ agar) then incubated at $30^{\circ} \mathrm{C}$ for $24 \mathrm{~h}$. The membrane was taken out from the plate and washed by TBST (20 mM Tris-Cl; $150 \mathrm{mM} \mathrm{NaCl} \mathrm{pH} \mathrm{7.6,} \mathrm{0.1 \%}$ Tween 20) until the colonies were washed out. The membrane was blocked by $5 \%$ skimmed milk in TBST for $1 \mathrm{~h}$ at room temperature, then washed three times with $10 \mathrm{~mL}$ TBST. The membrane was further incubated with Mouse insulin antibody mAb (1:500 in TBST) overnight at $8-10^{\circ} \mathrm{C}$, then washed three times with $10 \mathrm{~mL}$ TBST. The membrane was incubated again with Goat antimouse IgG antibody (H\&L) [HRP] (1:1000 in TBST) for 1 hour at room temperature, washed three times with $10 \mathrm{~mL}$ TBST, then $5 \mathrm{~mL}$ ChromoSensor ${ }^{\mathrm{TM}}$ One solution TMB substrate (GenScript, USA) was added, shaken at low speed at room temperature until color formed. 


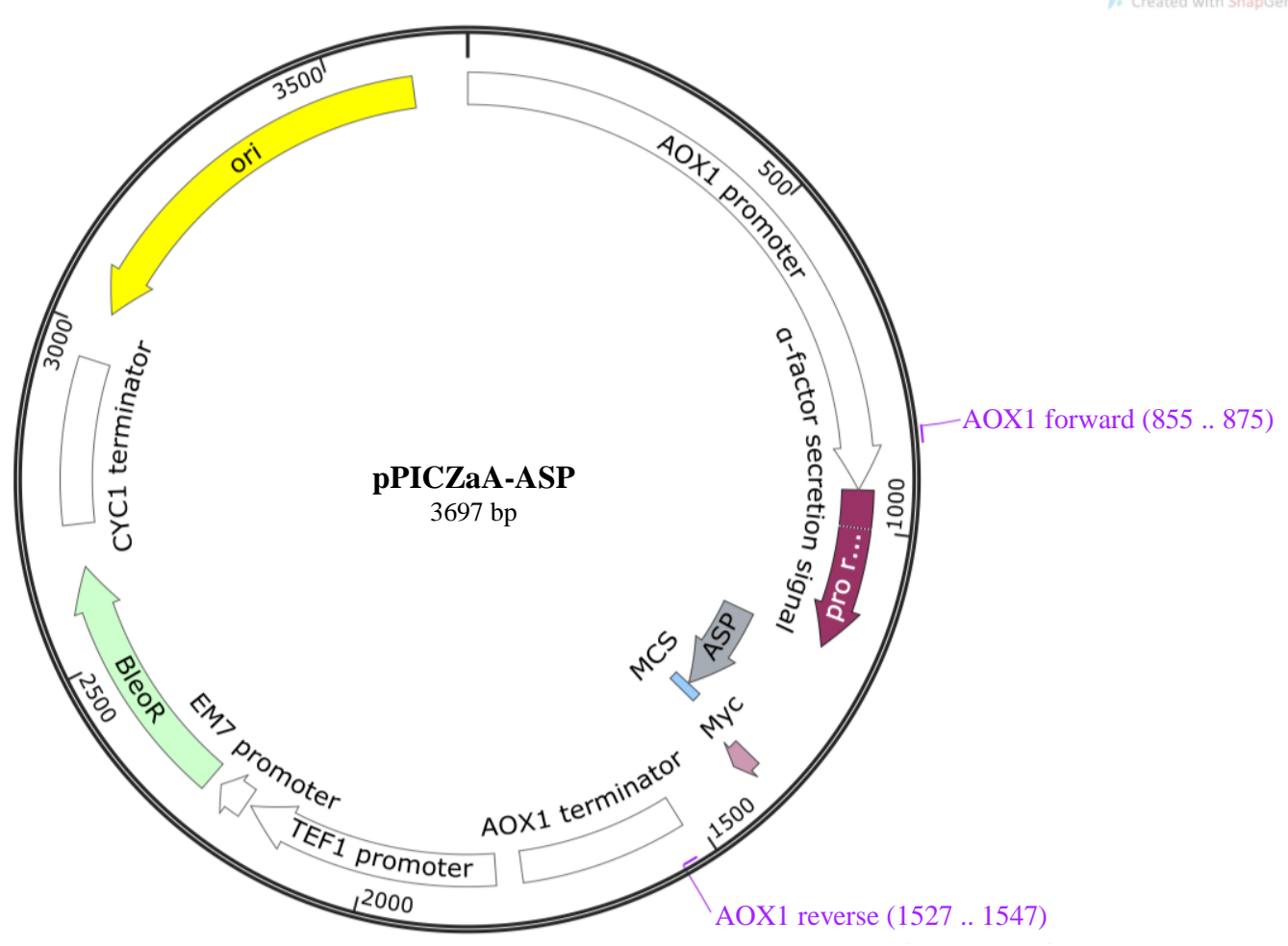

Fig. 1: The vector map of pPICZ $\alpha$ A-ASP

\section{Expression of Insulin Aspart Precursor}

$P$. pastoris harboring insulin Aspart precursor gene was grown in $10 \mathrm{~mL}$ YPD containing $100 \mu \mathrm{g} / \mathrm{mL}$ zeocin with shaking at $250 \mathrm{rpm}$ at $30^{\circ} \mathrm{C}$ for $18 \mathrm{~h}$. A volume of culture was transferred to $50 \mathrm{~mL}$ buffered glycerolcomplex (BMGY) medium which contained $1 \%$ yeast extract, $2 \%$ peptone, $100 \mathrm{mM}$ potassium phosphate buffer $\mathrm{pH} 6.0,1.34 \%$ yeast nitrogen base, $4 \times 10^{-5} \%$ biotin, and $1 \%$ glycerol in $500 \mathrm{~mL}$ flask to obtain an $\mathrm{OD}_{600}$ of 0.2 . The culture was further grown for $24 \mathrm{~h}$. The cells were harvested and resuspended in the medium of BMMY ( $1 \%$ yeast extract, $2 \%$ peptone, $100 \mathrm{mM}$ potassium phosphate buffer $\mathrm{pH} \quad 6.0,1.34 \%$ yeast nitrogen base, and $4 \times 10^{-5} \%$ biotin). The culture was induced by methanol every $24 \mathrm{~h}$ and further grown on shaking incubator at $225 \mathrm{rpm}$ and $30^{\circ} \mathrm{C}$. After $48 \mathrm{~h}$ of production, the culture was harvested by centrifugation at $3000 \times g$ for 15 minutes. The cells were stored at $-20^{\circ} \mathrm{C}$ and the supernatant was kept at $4{ }^{\circ} \mathrm{C}$ for further analysis.

Optimization of methanol concentration to induce the expression of insulin Aspart precursor was carried out using various final methanol concentration $(0.5,1,2$ and $3 \%$ ). A volume of methanol concentration was fed to 5 $\mathrm{mL}$ of BMMY culture in $50 \mathrm{~mL}$ flask to obtain each final concentration. The effect of initial cell density was studied by applying different initial $\mathrm{OD}_{600}$ of BMMY culture $\left(\mathrm{OD}_{600}\right.$ of $45,60,75,90$ and 105). The expression was induced by $3 \%$ methanol, at the same aeration (ratio culture volume to flask volume 1:10). A various ratio volume of BMMY culture to flask volume $(10 \mathrm{~mL}$ in $250 \mathrm{~mL}$ flask, $25 \mathrm{~mL}$ in $250 \mathrm{~mL}$ flask and 25 in $500 \mathrm{~mL}$ flask) was used to investigate the effect of aeration for insulin Aspart precursor expression level. The study was performed at the same initial $\mathrm{OD}_{600}$ of 60 with $3 \%$ of final concentration of methanol induction.

\section{SDS-PAGE and Western Blot}

The cell culture supernatant was precipitated by TCA according to Koontz (2014) prior to SDS-PAGE. Intracellular protein was isolated by TCA lysis as described in Baerends et al. (2000). The protein was dissolved in sample buffer and boiled for 10 minutes before loading. All samples were loaded according to $\mathrm{OD}_{600}$ of each cell culture. SDS-PAGE was conducted as described by Schägger (2006). The gel was stained by Coomassie blue staining, except the gels for further analysis with Western blot. All SDS-PAGE images were further analyzed by densitometer (TotalLab, England). Protein from the SDS-PAGE gel was transferred to nitrocellulose membrane using the eBlot Protein Transfer System (GenScript, USA). The membrane was blocked, incubated with antibodies and developed by ChromoSensor ${ }^{\mathrm{TM}}$ One solution TMB substrate with the same procedure of colony blot (see Screening of Transformant section). 


\section{LC-ESI-MS Intact Mass Analysis of Insulin Aspart Precursor}

The LC-ESI-MS intact mass analysis was undertaken at Australian Proteome Analysis Facility (APAF), Macquarie University, Australia. The Mass spectrometer QExactive Plus (Thermoscientific, USA) equipped with an electron-spray ionizer was used to acquire the ESI-MS data.

One $\mathrm{mg}$ of dried sample obtained from TCA precipitation of the cell culture supernatant was reconstituted in $100 \mu \mathrm{L} 0.1 \%$ formic acid. A dilution of 1:50 was prepared in $0.1 \%$ formic acid. Sample $(10 \mu \mathrm{L})$ was injected onto the analytical column (Waters XBridge $\mathrm{BEH} \mathrm{C} 4,2.1 \times 100 \mathrm{~mm}, 300 \AA$, $3.5 \mu \mathrm{m})$ at $40^{\circ} \mathrm{C}$ with a flow rate of $200 \mu \mathrm{L} / \mathrm{min}$. Protein was eluted from the column using a linear solvent gradient from mobile phase A $(0.1 \%$ formic acid): mobile phase B $(0.1 \%$ formic acid and $99.9 \%$ acetonitrile) of $85: 15$ to $55: 45$, over $10 \mathrm{~min}$. After elution, the column was cleaned with $90 \%$ buffer B for 2 min and then equilibrated with $15 \%$ buffer B for 2 min before next sample injection.

The reverse phase LC eluent was subjected to positive ion electrospray analysis in Full MS mode. The FT mass range was set $400-2,800 \mathrm{~m} / \mathrm{z}, 3.5 \mathrm{kV}$ spray voltage, sheath gas 25 , aux gas 5 , in-source CID $30 \mathrm{eV}$, orifice temperature $275^{\circ} \mathrm{C}$, resolution 17,500 , AGC target $3 \times 106$, S-lens RF level set to 80 , summed 10 microscans, maximum ion injection time 150 milliseconds.

The intact mass raw files were processed using Xcalibur. Expected masses were calculated using BioPharma Finder (v3.0). The deconvoluted monoisotopic masses were calculated using the online ESIprot calculator.

\section{Results and Discussion}

\section{The Expression Cassette of Insulin Aspart Precursor}

The synthetic ASP gene encodes a polypeptide consisting of 4 amino acids of Kex2 cleavage site -LEKRfollowed by insulin Aspart precursor, comprising of the B chain 1-30 amino acids, linker -RWR- and the A chain 1-21 amino acids (Fig. 2A). The synthetic ASP gene was codon optimized for expression in $P$. pastoris resulting in codon adaptation index of 0.857 and GC content of $41.8 \%$. The analysis was carried out using CAIcal server at http://genomes.urv.es/CAIcal/ (Puigbò et al., 2008) and the codon preference of $P$. pastoris was obtained from https://www.kazusa.or.jp/codon/. The gene was fused inframe with the pre-pro region of $\alpha$-factor signal peptide and expressed under the regulation of methanol inducible AOXI promoter (Fig. 2B).

\section{Colony Screening of P. pastoris Harboring Insulin Aspart Precursor Gene}

Screening of $P$. pastoris harbouring ASP gene was carried out by colony PCR. It was found that five out of nine transformants contained ASP (Fig. 3), as indicated by the presence of $692 \mathrm{bp}$ band correlated with the size of flanking region of the $A O X 1$ promoter inserted with the ASP gene (Fig. 1). Moreover, $P$. pastoris transformants carrying ASP was subjected to colony blot screening against insulin antibody to determine their ability in producing Asp (data not shown). One colony showing high intensity was then selected for further analysis.

\section{Optimization of Insulin Aspart Precursor Production}

Insulin Aspart precursor production in shake flask culture was optimized in terms of methanol concentration, cell density and aeration. The SDS-PAGE analysis of the culture supernatant showed the appearance of $6.3 \mathrm{kDa}$ protein band after methanol induction, but no protein band with the same molecular mass was detected on culture supernatant without methanol induction (Fig. 4). Methanol concentration of $0.5,1,2$ and $3 \%$ were used to induce the cultures every 24 hours for 2 days. The expression level of Insulin Aspart precursor increased as the supplied methanol concentration was leveled up, in which $3 \%$ methanol resulted in the highest insulin Aspart precursor expression (Fig. 5). Our finding is in agreement with Kupcsulik and Sevella (2004) which stated that specific product formation rate is strongly dependent on methanol level. The phenotype of colony used for insulin Aspart precursor production is $\mathrm{Mut}^{\mathrm{S}}$ which has slow ability to utilize methanol as sole carbon source. $\mathrm{Mut}^{\mathrm{s}}$ phenotype enables methanol accumulation for promoter activation in shake flask culture since the methanol is supplied once daily (Gandier and Master, 2018). The provided methanol in the medium will not be rapidly utilized to accelerate its growth but will be used instead for promoter induction.

The effect of cell density $\left(\mathrm{OD}_{600}\right)$ on the expression of insulin Aspart precursor was then investigated. The result showed that the expression of insulin Aspart precursor increased as cell density $\left(\mathrm{OD}_{600}\right)$ of 45 was levelled up to 60 and started to decline afterward (Fig. 6). The concentration of protein product in extracellular medium is proportionally correlated to the cell density (Macauley-Patrick et al., 2005). However, after the cell density reached $\mathrm{OD}_{600}$ of 60 , the expression level of insulin Aspart precursor decreased as the cell density declined.

In this study, the same aeration and methanol concentration was applied throughout the production. It is possible that the expression of insulin Aspart precursor is low due to the methanol and oxygen shortage. Higher cell concentration requires higher oxygen uptake (Çelik et al., 2009). Moreover, shake flask system has limitation in controlling the methanol uptake by the cells (MacauleyPatrick et al., 2005). 


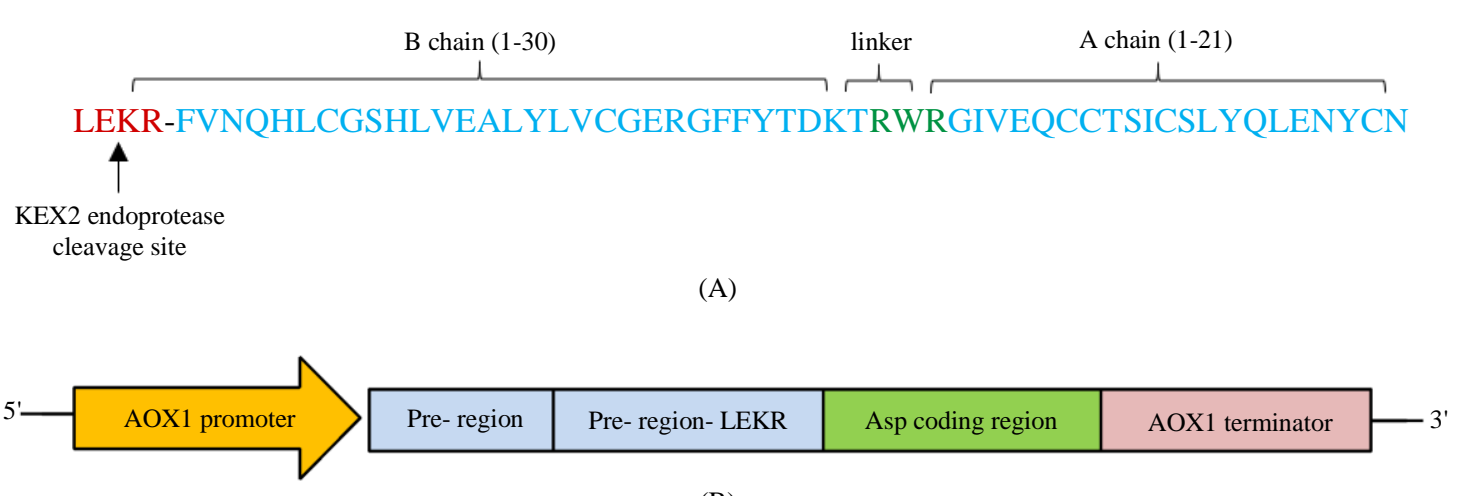

(B)

Fig. 2: (A) Amino acid sequences of insulin Aspart precursor; (B) The expression cassette of insulin Aspart precursor
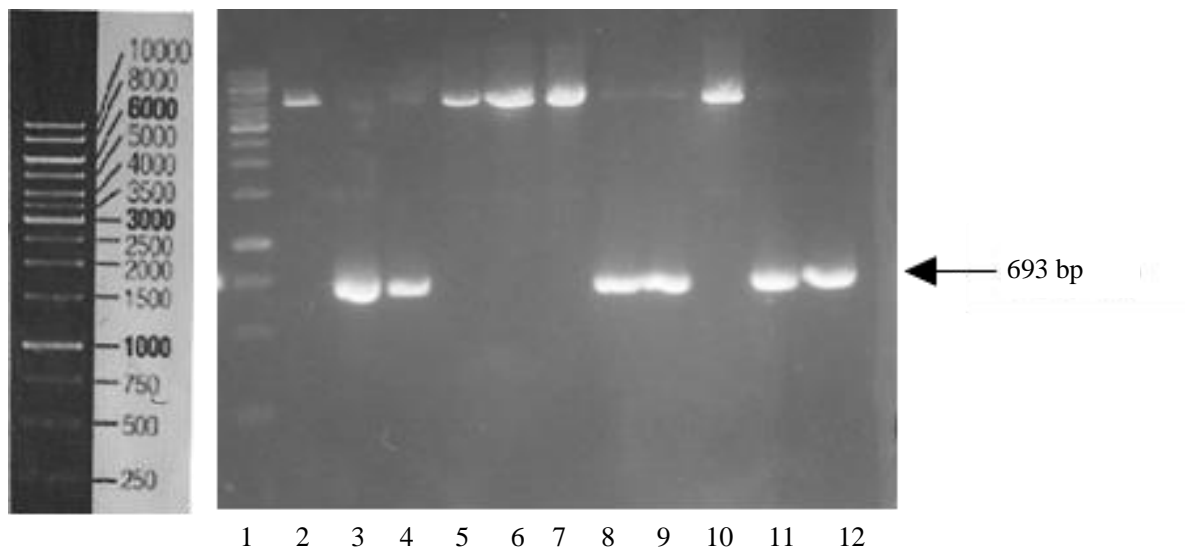

Fig. 3: Colonies of $P$. pastoris harbouring insulin Aspart precursor gene. Lane 1, $1 \mathrm{~kb}$ DNA ladder; lane 2, P. pastoris KM71; lane 3, positive control using pPICZaA-ASP; lanes 4 to 12, P. pastoris KM71 transformants with the colony carrying the Asp gene was indicated by $\sim 693$ bp of PCR product

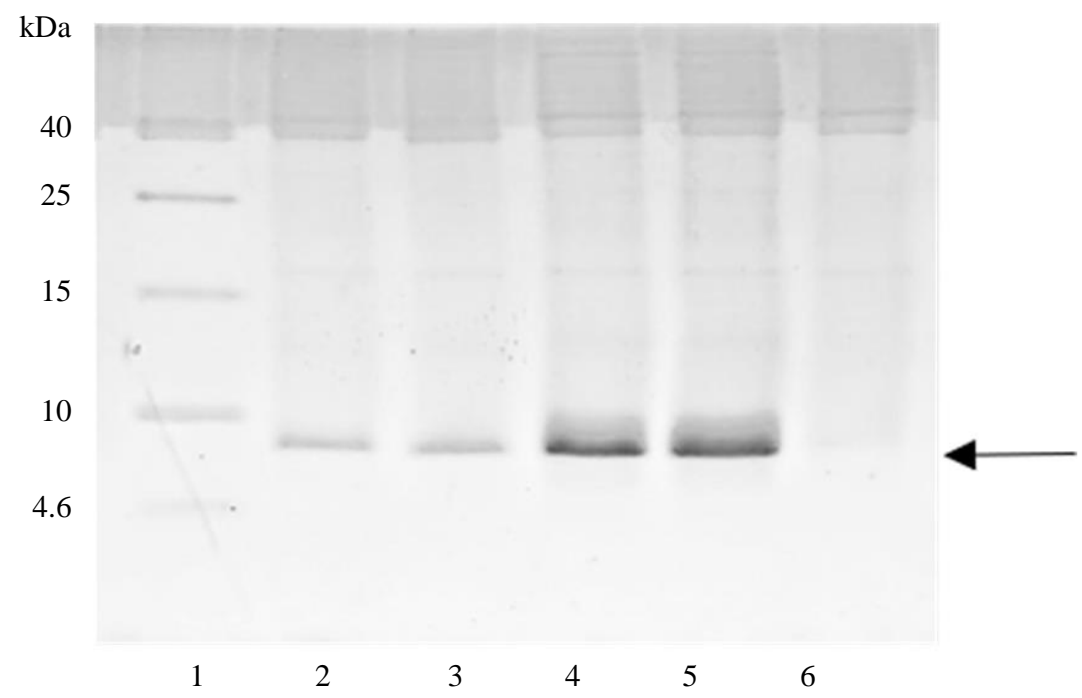

Fig. 4: Profiles of extracellular insulin Aspart precursor expressed at various concentration of methanol. Lane 1, protein marker; lanes 2 to 5 , methanol concentration of $0.5,1,2$ and $3 \%$, respectively; lane 6 , without methanol 


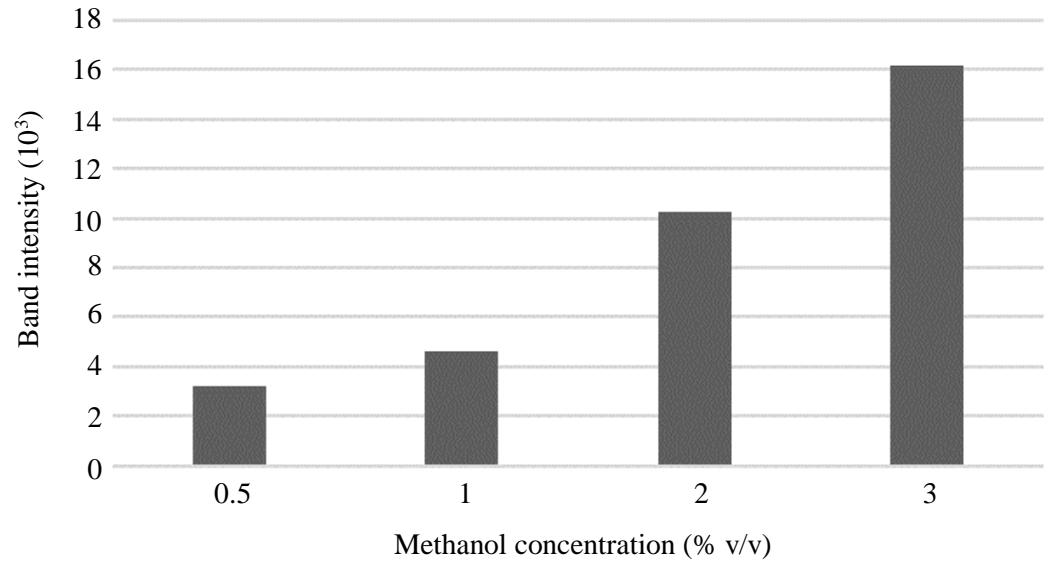

Fig. 5: Band intensity of insulin Aspart precursor expression at various concentrations of methanol

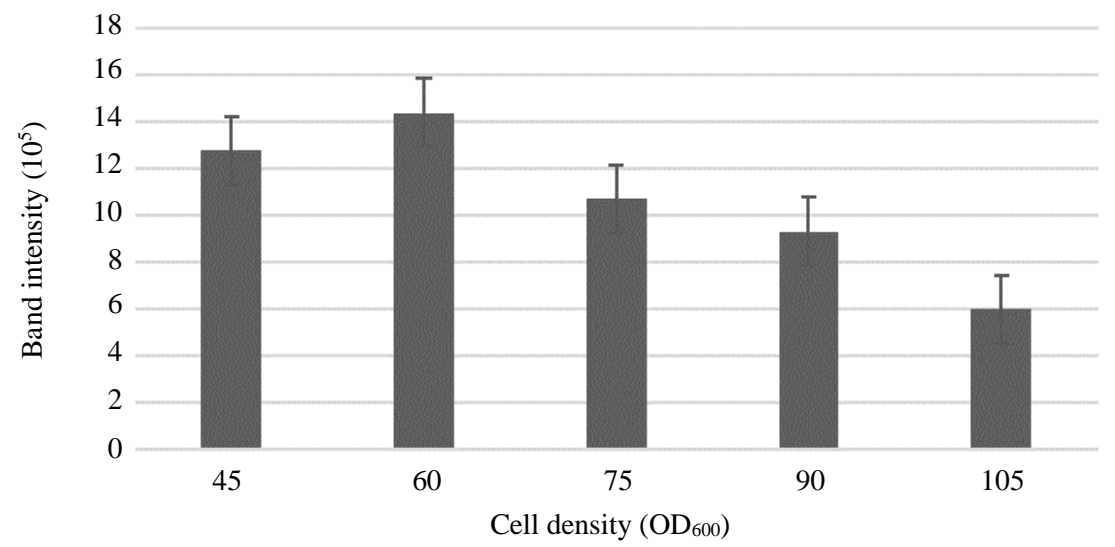

Fig. 6: Band intensity of insulin Aspart precursor expression at various cell density (OD600)

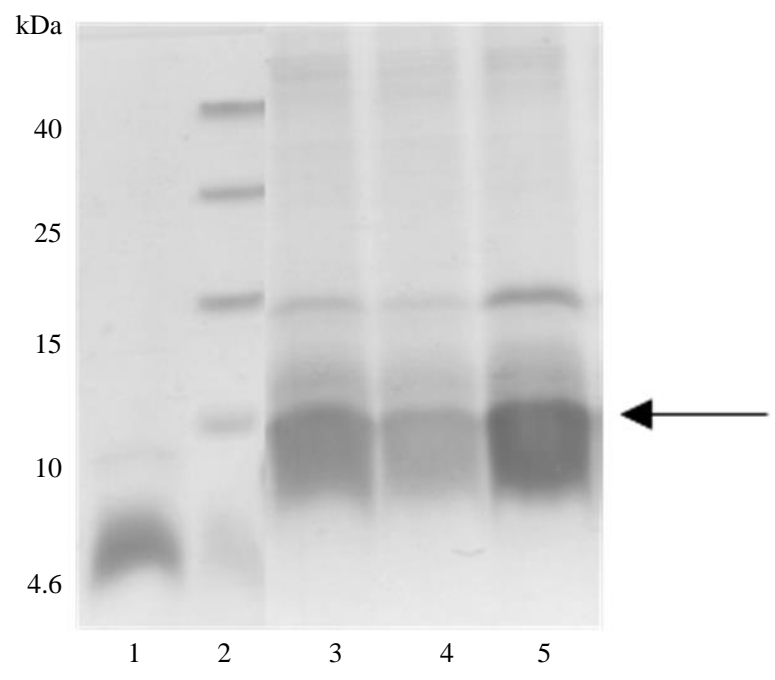

Fig. 7: Profiles of extracellular insulin Aspart precursor produced on various aeration. Lane 1, commercial bovine insulin; lane 2, protein ladder; lanes 3 to 5, ratio of culture volume to flask volume of 1:20, 1:10, 1:25, respectively 


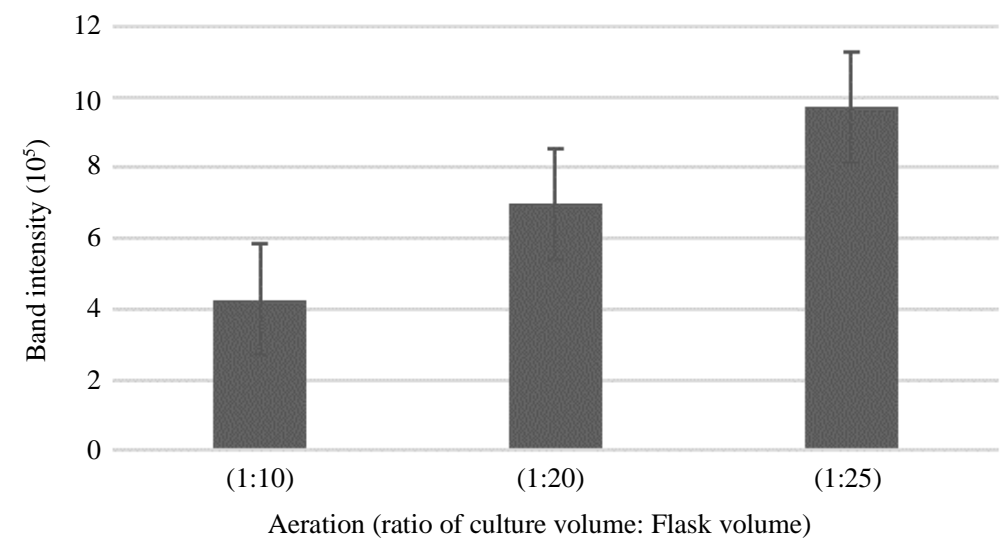

Fig. 8: Band intensity of insulin Aspart precursor expression in various aeration
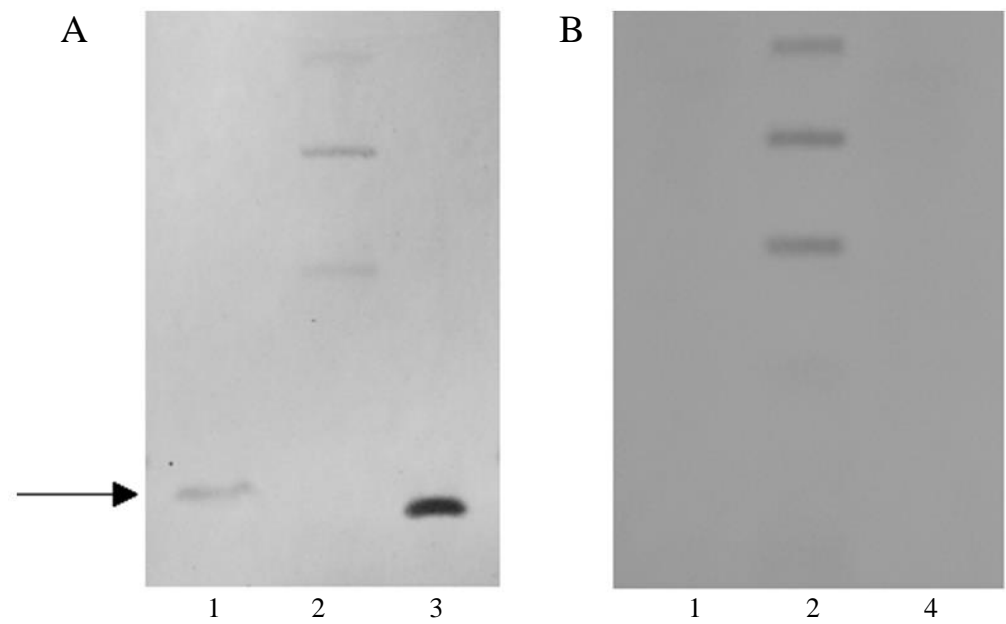

Fig. 9: Western blot of culture supernatant; (A) and intracellular fraction; (B) against insulin antibody. Lane 1, $P$. pastoris $\mathrm{KM} 71 / \mathrm{pPICZ} \alpha \mathrm{A}-\mathrm{ASP}$; lane 2, protein marker with molecular masses of 40, 25, and $15 \mathrm{kDa}$; lane 3 , commercial bovine insulin; lane 4, P. pastoris KM71

Furthermore, the effect of aeration to insulin Aspart precursor expression was investigated by applying various ratios of culture volume to flask volume. A gradual increase in insulin Aspart precursor expression was observed as the aeration ratio was risen from 1:10 to 1:25 (Fig. 7 and 8). Aeration is related to oxygen supply which is required for the growth of $P$. pastoris and heterologous protein expression. In shake flask, oxygen supply can be increased by raising the shaking speed or reducing culture volume (Yu et al., 2014).

\section{The Secretion of Insulin Aspart Precursor}

The secretion of insulin Aspart precursor was studied using Western blot analysis of extracellular and intracellular protein. According to Western blot analysis, insulin Aspart precursor was found in the culture medium and was not detected in the intracellular fraction (Fig. 9). This result indicates that the $\alpha$-MF signal peptide has been removed completely despite no spacer addition.

Further analysis by LC-ESI-MS showed that the molecular mass of insulin Aspart precursor is $6306.8 \mathrm{Da}$ and no other form of extracellular insulin Aspart precursor was detected (Fig. 10). The result suggested that the removal of spacer -EAEA- leads to insulin Aspart precursor secretion in its correct form and has no impact to the integrity of the product.

Kjeldsen et al. (1999) reported a different result of human insulin precursor expression in S. cerevisiae. The spacer was also removed from the constructed gene and a linker -SDDAK- was used to connect the C-terminal of $\mathrm{B}$ chain to the N-terminal of A chain of human insulin lacking its B30 amino acid. The result revealed an incomplete cleavage of the $\alpha-M F$ signal peptide and produced the hyperglycosylated fusion protein of $\alpha$-MF signal peptide and insulin precursor to the culture medium. 


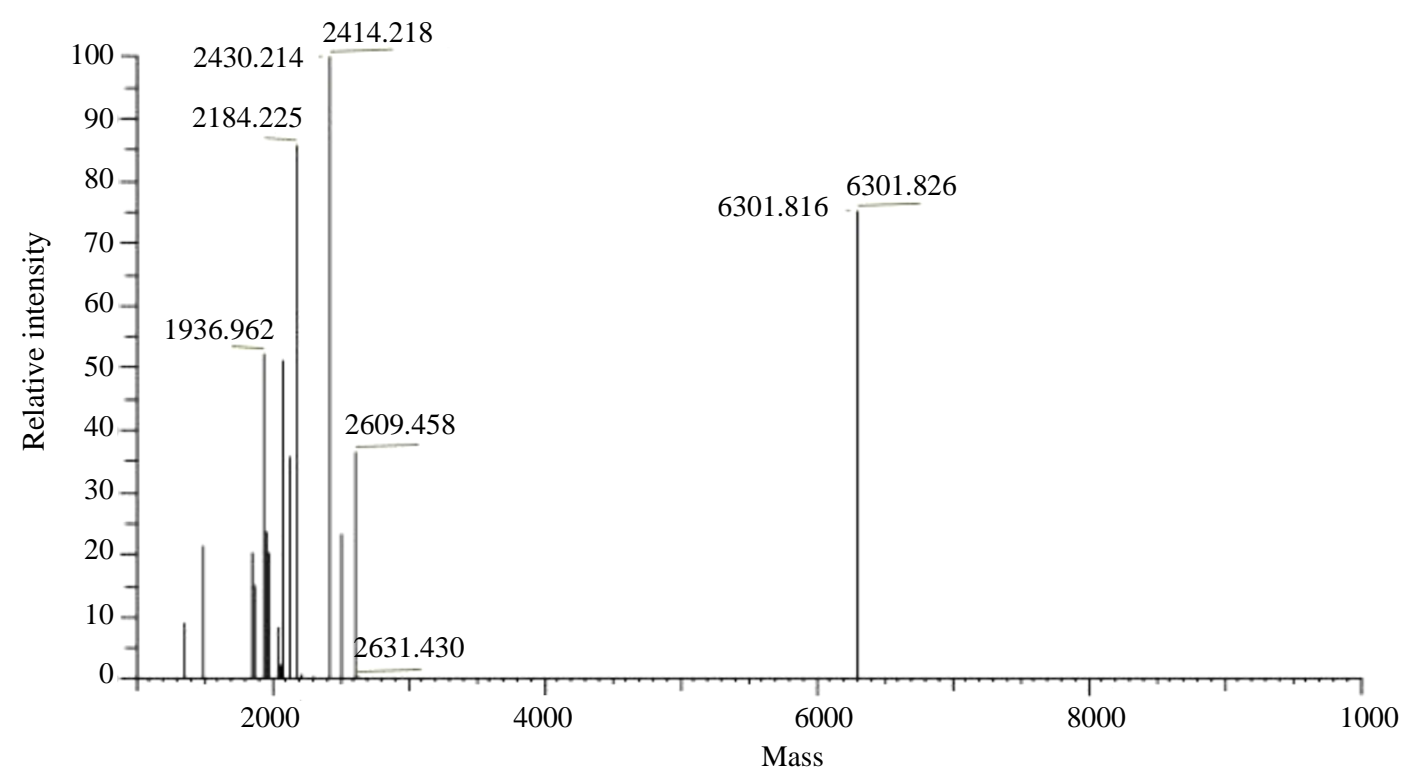

Fig. 10: ESI Mass spectrum of insulin Aspart precursor

It is possible that the use of different host cells leads to different signal peptide processing result. Although the core secretion pathway function in yeast is similar on genomic level (Delic et al., 2013), the morphological differences between $P$. pastoris and $S$. cerevisiae are observed (Papanikou and Glick, 2009). Generally, $P$. pastoris produces heterologous protein more efficiently compared to that of $S$. cerevisiae, due to these morphological differences (Zahrl et al., 2017). In terms of spacer function, our result showed that the presence of spacer -EAEA- is not necessary for insulin Aspart precursor secretion in $P$. pastoris, while the spacer is required in S. cerevisiae.

\section{Conclusion}

The gene encoding insulin Aspart precursor was successfully expressed extracellularly in $P$. pastoris KM71. The optimal condition for shake flask production of insulin Aspart precursor was achieved at 3\% methanol induction every $24 \mathrm{~h}$ for two days with initial cell density $\left(\mathrm{OD}_{600}\right)$ of 60 and aeration (ratio of culture volume to flask volume) of 1:25. Only the correct form of insulin Aspart precursor with molecular mass of $6301.8 \mathrm{Da}$ was observed suggesting that the cleavage of the $\alpha$-MF signal peptide without -EAEA- spacer is completed and the removal of the spacer resulted in insulin Aspart precursor.

\section{Acknowledgment}

This research was funded partially by Doctoral Research Grant from Ministry of Research, Technology and Higher Education of the Republic of Indonesia.
Aspects of this research have been facilitated by access to the Australian Proteome Analysis Facility supported under the Australian Government's National Collaborative Research Infrastructure Strategy (NCRIS).

\section{Authors Contribution}

Popi Asri Kurniatin: Performed all experiments, conducted data analysis and prepared the manuscript.

Fifi Fitriyah Masduki: Contributed in Western blot data analysis.

Neni Nurainy: Participated in production optimization and data-analysis.

Ihsanawati: Handled data analysis and prepared the manuscript.

Dessy Natalia: Designed the whole experiments, conducted data analysis and prepared the manuscript.

\section{Ethics}

All authors read and approved the final version of this manuscript. There are no ethical issues to declare that could arise after the publication of this manuscript.

\section{References}

Annibali, N., M. Goin, G. Trejo, F. Carrizo and D. Baruque, 2014. Process for obtaining Aspart insulin using a Pichia pastoris yeast Strain. US Patent, No. US 8691530 B2. 
Baerends, R.J.S., K.N. Faber, A.M. Kram, J.A.K.W. Kiel and I.J. van der Klei et al., 2000. A stretch of positively charged amino acids at the $\mathrm{N}$ terminus of Hansenula polymorpha Pex3p is involved in incorporation of the protein into the peroxisomal membrane. J. Biol. Chem., 275: 9986-9995.

DOI: $10.1074 /$ jbc.275.14.9986

Baeshen, N.A., M.N. Baeshen, A. Sheikh, R.S. Bora and M.M.M. Ahmed et al., 2014. Cell factories for insulin production. Microbial. Cell Factories, 13: 141-141. DOI: 10.1186/s12934-014-0141-0

Brenner, C. and R.S. Fuller, 1992. Structural and enzymatic characterization of a purified prohormone-processing enzyme: Secreted, soluble Kex2 protease. Proc. Nat. Acad. Sci., 89: 922-926. DOI: $10.1073 /$ pnas.89.3.922

Cregg, J.M. and K.A. Russell, 1998. Transformation. In: Pichia Protocols, Methods in Molecular Biology, Higgins, D.R. and J.M. Cregg (Eds.), Humana Press Inc., Totowa, NJ, pp: 27-39.

Çelik, E., P. Çalık and S.G. Oliver, 2009. Fed-batch methanol feeding strategy for recombinant protein production by Pichia pastoris in the presence of cosubstrate sorbitol. Yeast, 26: 473-484.

DOI: 10.1002/yea.1679

Daly, R. and M.T.W. Hearn, 2005. Expression of heterologous proteins in Pichia pastoris: A useful experimental tool in protein engineering and production. J. Molecular Recognit., 18: 119-138. DOI: 10.1002/jmr.687

Delic, M., M. Valli, A.B. Graf, M. Pfeffer and D. Mattanovich et al., 2013. The secretory pathway: Exploring yeast diversity. FEMS Microbiol. Rev., 37: 872-914. DOI: 10.1111/1574-6976.12020

Gandier, J.A. and E. Master, 2018. Pichia pastoris is a suitable host for the heterologous expression of predicted class I and class II hydrophobins for discovery, study and application in biotechnology. Microorganisms, 6: 3-3.

DOI: $10.3390 /$ microorganisms6010003

Gurramkonda, C., S. Polez, N. Skoko, A. Adnan and T. Gäbel et al., 2010. Application of simple fed-batch technique to high-level secretory production of insulin precursor using Pichia pastoris with subsequent purification and conversion to human insulin. Microbial. Cell Factories, 9: 31-31.

DOI: 10.1186/1475-2859-9-31.

Kurjan, J. and I. Herskowitz, 1982. Structure of a yeast pheromone gene $(\mathrm{MF} \alpha)$ : A putative $\alpha$-factor precursor contains four tandem copies of mature $\alpha$ factor. Cell, 30: 933-943. PMID: 6754095, DOI: 10.1016/0092-8674(82)90298-7.
Kjeldsen, T., A.F. Pettersson and M. Hach, 1999. Secretory expression and characterization of insulin in Pichia pastoris. Biotechnol. Applied Biochem, 29: 79-86. PMID: 9889087

Koontz, L., 2014. TCA Precipitation. In: Methods in Enzymology, Elsevier Inc., pp: 3-10.

Kupcsulik, B. and B. Sevella, 2004. Effect of methanol concentration on the recombinant Pichia pastoris Mut $^{\mathrm{S}}$ fermentation. Periodica Polytechnica Ser. Chem. Eng., 48: 73-78.

Leader, B., Q.J. Baca and D.E. Golan, 2008. Protein therapeutics: A summary and pharmacological classification. Nature Rev. Drug Dis., 7: 21-39. DOI: $10.1038 / \mathrm{nrd} 2399$

Lin-Cereghino, G.P., C.M. Stark, D. Kim, J. Chang and N. Shaheen et al., 2013. The effect of $\alpha$-mating factor secretion signal mutations on recombinant protein expression in Pichia pastoris. Gene, 519: 311-317. DOI: 10.1016/j.gene.2013.01.062

Macauley-Patrick, S., M.L. Fazenda, B. McNeil and L.M. Harvey, 2005. Heterologous protein production using the Pichia pastoris expression system. Yeast, 22: 249-270. DOI: $10.1002 /$ yea. 1208

Papanikou, E. and B.S. Glick, 2009. The yeast Golgi apparatus: Insights and mysteries. FEBS Lett., 583: 3746-3751. DOI: 10.1016/j.febslet.2009.10.072

Polez, S., D. Origi, S. Zahariev, C. Guarnaccia and S.G. Tisminetzky et al., 2016. A simplified and efficient process for insulin production in Pichia pastoris. PLOS ONE, 11: e0167207-e0167207.

DOI: 10.1371/journal.pone.0167207

Puigbò, P., I.G. Bravo and S. Garcia-Vallve, 2008. CAIcal: A combined set of tools to assess codon usage adaptation. Biol. Direct, 3: 38-38.

DOI: 10.1186/1745-6150-3-38

Schägger, H., 2006. Tricine-SDS-PAGE. Nature Protocols, 1: 16-22. DOI: 10.1038/nprot.2006.4.

Thim, L., M.T. Hansen, K. Norris, I. Hoegh and E. Boel et al., 1986. Secretion and processing of insulin precursors in yeast. Proc. National Academy Sci., 83: 6766-6770.

DOI: $10.1073 /$ pnas.83.18.6766

Tibaldi, J.M., 2014. Evolution of insulin: From human to analog. Am. J. Med., 127: S25-S38.

DOI: 10.1016/j.amjmed.2014.07.005

Wang, Y., Z.H. Liang, Y.S. Zhang, S.Y. Yao and Y.G. $\mathrm{Xu}$ et al., 2001. Human insulin from a precursor overexpressed in the methylotrophic yeast Pichia pastoris and a simple procedure for purifying the expression product. Biotechnol. Bioengineer., 73: 74-79. DOI: 10.1002/10970290(20010405)73:1<74::AID-BIT1038>3.0.CO;2-V 
Popi Asri Kurniatin et al. / American Journal of Biochemistry and Biotechnology 2019, 15 (4): 198.207 DOI: 10.3844/ajbbsp.2019.198.207

Xie, T., Q. Liu, F. Xie, H. Liu and Y. Zhang, 2008. Secretory expression of insulin precursor in Pichia pastoris and simple procedure for producing recombinant human insulin. Preparative Biochem. Biotechnol., 38: 308-317.

DOI: $10.1080 / 10826060802165147$

Yu, Y., X. Zhou, S. Wu, T. Wei and L. Yu, 2014. Highyield production of the human lysozyme by Pichia pastoris SMD1168 using response surface methodology and high-cell-density fermentation. Electronic J. Biotechnol., 17: 311-316.

DOI: 10.1016/j.ejbt.2014.09.006
Zahrl, R.J., D.A. Peña, D. Mattanovich and B. Gasser, 2017. Systems biotechnology for protein production in Pichia pastoris. FEMS Yeast Res., 17: 1-15. DOI: $10.1093 /$ femsyr/fox068 